\title{
A New Control Strategy for Smoothing of Wind Farm Output using Short- Term Ahead Wind Speed Prediction and Flywheel Energy Storage System
}

Farzana Islam ${ }^{1}$, Hany. Hasanien ${ }^{2}$, Ahmed Al-Durra ${ }^{1}$, S.M.Muyeen ${ }^{1}$

${ }^{1}$ Department of Electrical Engineering, The Petroleum Institute Abu Dhabi, UAE

${ }^{2}$ Electrical Power and Machines Department, Ain Shams University, Cairo, Egypt

E-mail: fislam@pi.ac.ae

\begin{abstract}
With the increased integration of wind energy into power networks it has become more important to have a reliable system for mitigating the fluctuations of output power supplied to the grid. This paper proposes a new control scheme to smooth the output power fluctuations of an aggregated wind firm using Flywheel energy storage system (FESS) and shortterm ahead prediction of wind speed. In the proposed system, the kinetic energy of the FEES is utilized to smooth the output power fluctuations of wind farm. In addition, the stored energy of FESS is utilized in most efficient way by correcting the power reference using prediction base control. This helps to reduce the overall system cost by keeping the size of the energy storage system at minimum. The effectiveness of the proposed control is verified by using PSCAD/EMTDC.
\end{abstract}

Keywords: Doubly-fed Induction Generator (DFIG), Flywhee energy storage Systems (FESS), Output power smoothing, Wind speed prediction.

\section{INTRODUCTION}

Wind energy is now considered to be the world's fastest growing renewable energy due to the environmental concern and depletion of fossil fuels. There has been a rapid growth of wind energy since last decade. Wind power capacity during 2010 has reached $39000 \mathrm{MW}$ which is almost three times the $11500 \mathrm{MW}$ of the rated wind power added by last five years. The existing capacity has increased more than $24 \%$ as compared to 2009 [1]. However, the intermittent nature of wind speed makes a big issue in the generation of wind power. As the output power of the turbine varies with the cube of wind speed, a small change in the wind speed can make a big variation in the farm's output. Frequency deviation in the grid is mainly due to the power fluctuation in the output of wind generators and this imposes some restrictions to install new wind farms. Therefore, it is essential to mitigate the fluctuations of wind generator output power and hence improve the quality of the power delivered to the grid.

Accurate prediction of wind speed is beneficial for power grid management, matching demand \& supply and in stabilization of power system [2]. Several methods have been already proposed for the forecasting of the wind speed using different techniques such as linear regression analysis, time series, fuzzy linear regression method etc. [3-5].In addition, smoothing of output power of wind farm (WF) can be also achieved considering different kinds of energy storage devices. In general, Battery energy storage system (BESS), super conducting magnetic energy storage systems (SMES), energy capacitor systems (ECS) or flywheel energy storage systems (FESS) etc. [6-7] are used for the purpose of power smoothing.

Recently, flywheel energy storage systems (FESS) using rotational machines have become more popular because of their reliability, long life, large energy storage capacity, and less overall cost. FESS with Doubly-fed Induction Generator (DFIG) can improve the power system stability as DFIG not only supplies the real power but also it can compensate reactive power demand rapidly and independently. Hence, the reactive power compensation of the system can be achieved at lower cost.

This paper proposes a new control strategy to smooth the output power fluctuation of Wind Turbine Generator (WTG) by using FESS. In addition, prediction of wind speed using short-term ahead linear regression method is also considered. Due to its simplicity, linear regressions model has been chosen rather than other complex forecasting techniques available. The Inertia constant of the Flywheel is considered to be $30 \mathrm{~s}$ which is sufficient enough to smooth the output fluctuations and hence the size of the energy storage system becomes small, which decreases overall cost of the system. The reference power of the WF is adjusted according to the availability of the stored energy in the FESS with the predicted wind speed data. FESS can supply or absorb power according to the proper adjustment of reference power. Hence, the prediction scheme helps to keep the overall installation cost minimum by optimum use of stored energy in a small FESS.

In section II, the dynamic modeling of the proposed system is described. In section III, modeling of individual system components including the control strategy for the proposed model and how prediction scheme associated with control strategy smoothes the output power fluctuations are explained. Simulation results are shown in Section IV and finally, conclusions are given in the last section. In order to have an effective control strategy real wind speed data is used for simulation. Simulation analysis is performed using PSCAD/EMTDC [8].

\section{MODEL SYSTEM}

The Model system used in this study is shown in Fig. 1. Aggregated type of wind farm using induction generator (IG) is considered. The IG (10MVA) is connected to an infinite bus through the transformer and transmission line. The FESS (5MVA) is connected at the grid point of WF. Doubly-fed induction generator (DFIG) with secondary 
excitation system is considered as FESS. The parameters of the IG and FESS are shown in Table I.

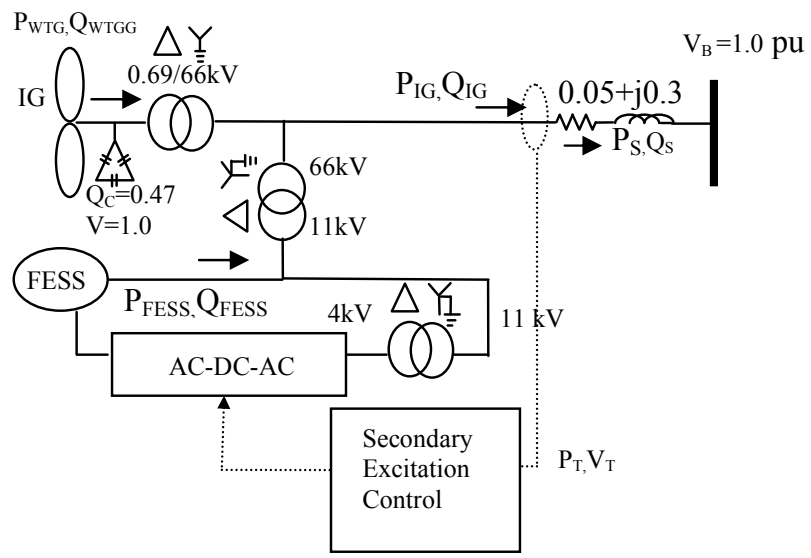

Fig. 1. Model system

\section{Modeling AND CONTROL SCHEME}

A. Wind Turbine Model

The WF consists of an IG and a wind turbine. The aerodynamic power capture by the wind is given by (1).Tip Speed Ratio $(\lambda)$ and power co efficient $\left(\mathrm{C}_{\mathrm{P}}\right)$ can be expressed as (2), (3), (4) [9-13].

$$
\begin{aligned}
& P_{m}=\frac{1}{2} \cdot \rho C_{P}(\lambda) \pi R^{2} V_{W}^{3} \\
& \lambda=\frac{\omega_{m} R}{V_{w}} \\
& C_{P}(\lambda, \beta)=\frac{1}{2} \cdot\left(\Gamma-0.02 \beta^{2}-5.6\right) e^{-0.17 \Gamma} \\
& \Gamma=\frac{R(3600)}{\lambda(1609)}
\end{aligned}
$$

The torque coefficient $\left(\mathrm{C}_{\mathrm{t}}\right)$ and turbine torque are given below:

$$
\begin{aligned}
& C_{t}(\lambda)=\frac{C_{P}(\lambda)}{\lambda} \\
& T_{m}=\frac{1}{2} \cdot \rho C_{t}(\lambda) \pi R^{3} V_{W}{ }^{2}
\end{aligned}
$$

Where $\mathrm{P}_{\mathrm{m}}$ is the wind turbine output [W], $\mathrm{R}$ is the radius of the blade[m], $\omega$ is the angular speed of wind turbine $[\mathrm{rad} / \mathrm{s}]$, is the blade pitch angle [deg], $V_{w}$ is the wind speed[m/s], $\rho$ is the air density $\left[\mathrm{kg} / \mathrm{m}^{3}\right]$ and $\mathrm{T}_{\mathrm{m}}$ is the wind turbine output torque $[\mathrm{Nm}]$.

\section{B. Double Fed Induction Generator Model}

The DFIG can be modeled by the following equations (710) [14] in the direct (d) and quadrature (q) axis reference frame, which is rotating at synchronous speed $(\omega=2 \pi \mathrm{f})$ :

Stator voltage and rotor voltage:

$$
\begin{aligned}
& u_{s d}=-R_{s} i_{s d}-p \psi_{s d}+\omega_{1} \psi_{s q} \\
& u_{s q}=-R_{s} i_{s q}-p \psi_{s q}-\omega_{1} \psi_{s d} \\
& u_{r d}=R_{r} i_{r d}+p \psi_{r d}-\omega_{s} \psi_{r q} \\
& u_{r q}=R_{r} i_{r q}+p \psi_{r q}+\omega_{s} \psi_{r d}
\end{aligned}
$$

Stator flux and rotor flux:

$$
\begin{array}{ll}
\psi_{s d}=L_{s} i_{s d}-L_{m} i_{r d} & \psi_{r d}=L_{r} i_{r d}-L_{m} i_{s d} \\
\psi_{s q}=L_{s} i_{s q}-L_{m} i_{r q} & \psi_{r q}=L_{r} i_{r q}-L_{m} i_{s q}
\end{array}
$$

Rotor swing equation:

$$
T_{m}-T_{e}=-T_{e}=\frac{J}{n_{P}} \frac{d \omega_{r}}{d t}+\frac{D}{n_{P}} \omega_{r}
$$

Stator Power:

$$
\begin{gathered}
P_{s}=u_{s d} i_{s d}+u_{s q} i_{s q} \\
Q_{s}=u_{s q} i_{s d}-u_{s d} i_{s q}
\end{gathered}
$$

Where, $\mathrm{u}$ is the voltage, $\mathrm{I}$ is the current, $\mathrm{R}$ is the resistance, $\mathrm{L}$ is reactance, $\psi$ is the flux linkage, $\psi_{1}$ and $\psi_{\mathrm{r}}$ are the stator and rotor electrical angular speed respectively. The direct and quadrature axis components under the rotation synchronizing reference frame are indicated by $\mathrm{d}$ and $\mathrm{q}$ axis. Damping torque is proportional to the rotor angular speed and it is indicated by D. $\mathrm{n}_{\mathrm{P}}$ and $\mathrm{J}$ are considered as number of pole pairs and rotor inertia respectively. $\mathrm{S}, \mathrm{r}$ and $\mathrm{m}$ indicate stator, rotor and mutual quantities respectively. $T_{m}$ is mechanical torque.

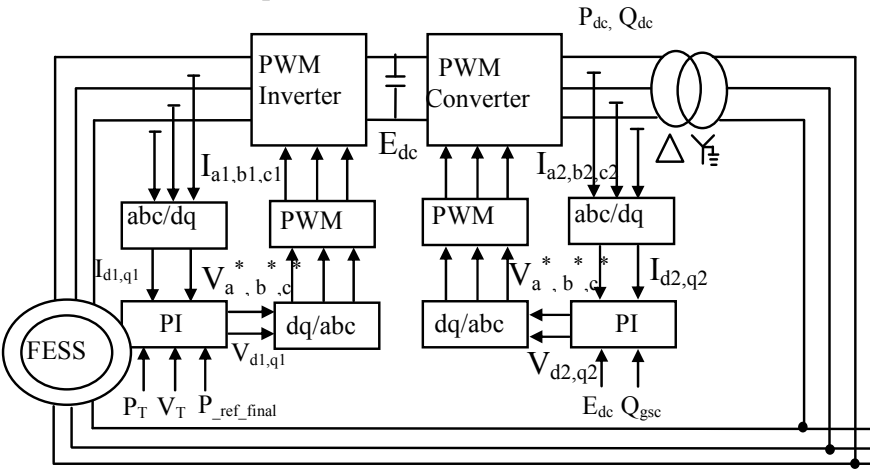

Fig. 2. Secondary excitation system for FESS

Network

TABLE I

IG AND FESS PARAMETERS

\begin{tabular}{|l|c|c|}
\hline & IG & FESS \\
\hline Stator resistance (p.u.) & 0.01 & 0.02 \\
\hline Stator leakage reactance (p.u.) & 0.1 & 0.05 \\
\hline Magnetizing reactance (p.u.) & 3.5 & 4.01 \\
\hline Rotor resistance (p.u.) & 0.01 & 0.02 \\
\hline Rotor leakage reactance (p.u.) & 0.12 & 0.05 \\
\hline Inertia Constant, H (sec) & 1.5 & 15 \\
\hline
\end{tabular}

\section{Configuration of FESS}

In this paper DFIG with secondary excitation system is considered as FESS as shown in Fig. 2. FESS is a mechanical energy storage system where energy is stored in 
the form of kinetic energy. The maximum and minimum energy that can be stored in the FESS is limited to $\pm 30 \%$ of the rated energy. In FESS, a part of the stator output power is supplied to the rotor side converter where it is converted into DC power. This DC power is again converted into AC power and then supplied to the rotor [13]. DC-link relevant parameters are given in Table II. The reference of the output power for the secondary excitation circuit is adjusted according to the availability of the stored energy in FESS and the predicted wind speed data.

TABLE II

FESS PARAMETER

\begin{tabular}{|l|l|}
\hline Parameters & FESS \\
\hline DC link voltage $(\mathrm{kV})$ & 4.0 \\
\hline DC link capacitance $(\boldsymbol{\mu F})$ & 50000 \\
\hline
\end{tabular}

\section{Rotor Side Converter(RSC):}

The function of rotor side converter (RSC) is to control the active and reactive power control of the stator side. The control for RSC is shown in Fig. 3.

\section{E. Grid Side Converter(GSC):}

The function of grid side converter (GSC) is to keep the DC link voltage constant at 1 p.u. and also to supply additional reactive power into the grid. The control for GSC is shown in Fig. 4.
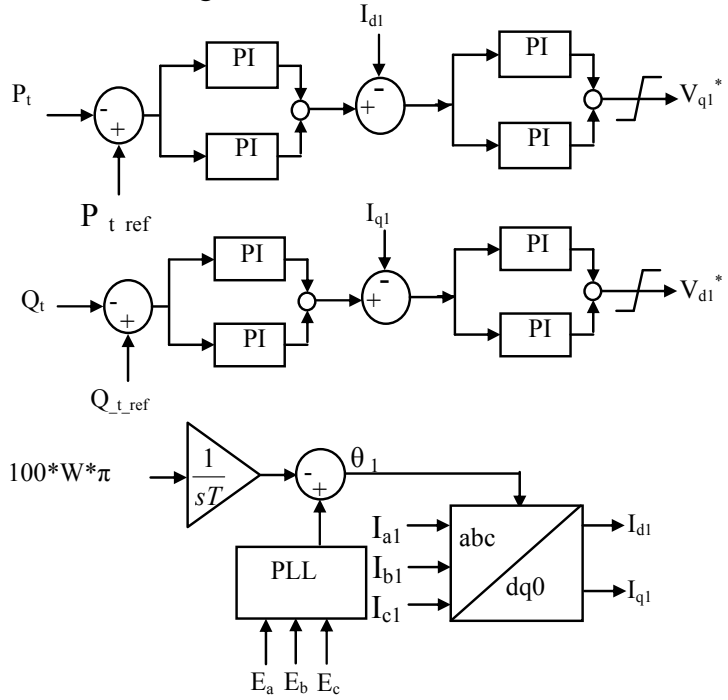

Fig. 3. Control block for RSC

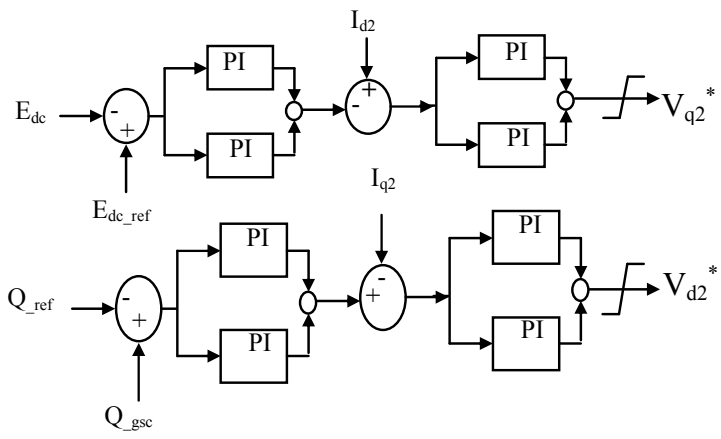

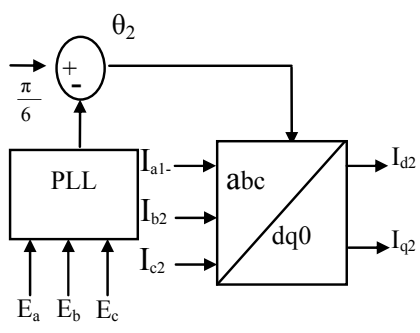

Fig. 4. Control block for GSC

F. Control scheme for smoothing of output power by using FESS:

The output of the wind generator changes arbitrarily with the change of wind speed. As a result, the output power reference has to be adjusted with the change of wind speed. The reference output ( $\mathrm{P}$ ref 1 ) is generated using low pass filter function, where ( $\mathrm{P}_{-}$Predict $\left.+\mathrm{P}_{-} \mathrm{IG}\right) / 2$ is considered as the input of the filter function. The time constant of the filter function is chosen as $180 \mathrm{~s}$. When the output of the IG is higher than the final output power reference, FESS is in charging mode and absorbs the active power from the grid. But when the generated output is lower than the final output power reference, FESS is in discharging mode and supplies active power to the grid. The maximum and minimum rotor speed of FESS is considered as $130 \%$ (1.3 p.u.) and 70\% ( 0.7 p.u.) of the rated speed, respectively. The control strategy for this purpose is designed in such a way that the actual energy of FESS could vary within a range close to 0.75 p.u. at which the stored energy becomes half of the maximum stored energy. By controlling the rotor speed of FESS in different operating regions, the stored energy in FESS is utilized to smooth the output power fluctuation. The control strategy used for the system is shown in Fig. 5. Flowchart shown in Fig. 6 is used to avoid any excess or shortage of required energy in FESS. Energy is calculated based on rotor speed of FESS system.

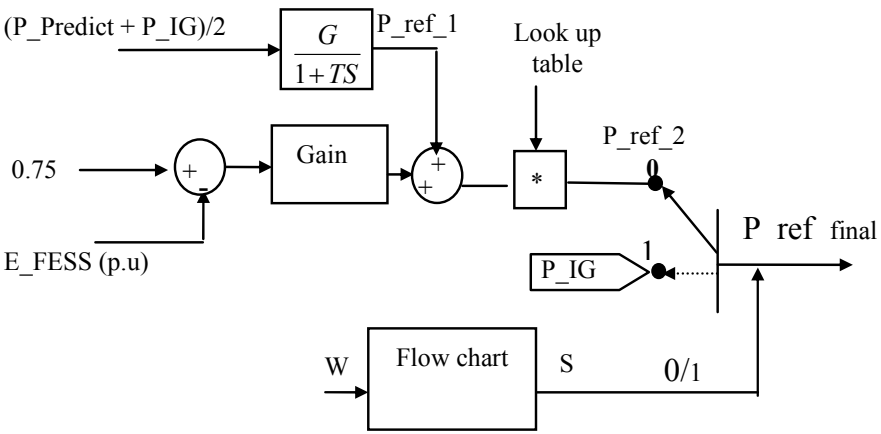

Fig. 5. Reference signal generation scheme for FESS

G. Wind speed Prediction by using linear regression model:

In this paper, wind speed data is predicted using shortterm ahead linear regression model. The model equation is given by (11) [15].

$$
y_{i}=b_{0}+b_{1} x_{i, 1}+b_{2} x_{i, 2}+\ldots+b_{k} x_{i, k}+e_{i}
$$


Where $x_{i, k}=$ value of $\mathrm{k}^{\text {th }}$ predictor in time $\mathrm{i}$

$b_{o}=$ regression constant

$b_{k}=$ coefficient on the $\mathrm{k}^{\text {th }}$ predictor

$\mathrm{K}=$ total number of predictors

$y_{i}=$ predicted in time $\mathrm{i}$

$e_{i}=$ error term

Equation (11) is estimated by least squares. The resulting prediction equation is given by (12).

$$
\hat{y}_{i}=\hat{b}_{0}+\hat{b}_{1} x_{i, 1}+\hat{b}_{2} x_{i, 2}+\ldots+\hat{b}_{k} x_{i, k}
$$

The regression residuals are defined as (13).

$$
\hat{e}_{i}=y_{i}-\hat{y}_{i}
$$

Where $y_{i}=$ observed value of predicted in time $i$

$\hat{y}_{i}=$ predicted value of predicted in time $i$

In this paper, the prediction model has been implemented using MATLAB. Since the data for wind speed can be predicted prior to actual wind speed data, this is used to adjust the power reference according to the availability of actual energy. The predicted power is calculated by using (14).

$$
P_{\text {predicted }}=\frac{1}{2} \cdot \rho C_{P}(\lambda) \pi R^{2} V_{\text {Wpredicted }}^{3}
$$

If the difference between the predicted power ( $\mathrm{P}$ _Predict) and actual power (P_IG) is small and the actual stored energy of FESS is in a range of (45-85)\% of the rated energy, then the control of the reference signal generation is designed in such a way that there is no need to modify the output power reference.

On the other hand, if the available energy is not in the above mentioned range then the reference, P_ref_2 is corrected according to the values stored in a look up table. Finally, Flowchart 1 is used to modify the final output reference (P_ref_final) as shown in in Fig. 6 to maintain stability of FESS system when speed goes behind or beyond threshold values.

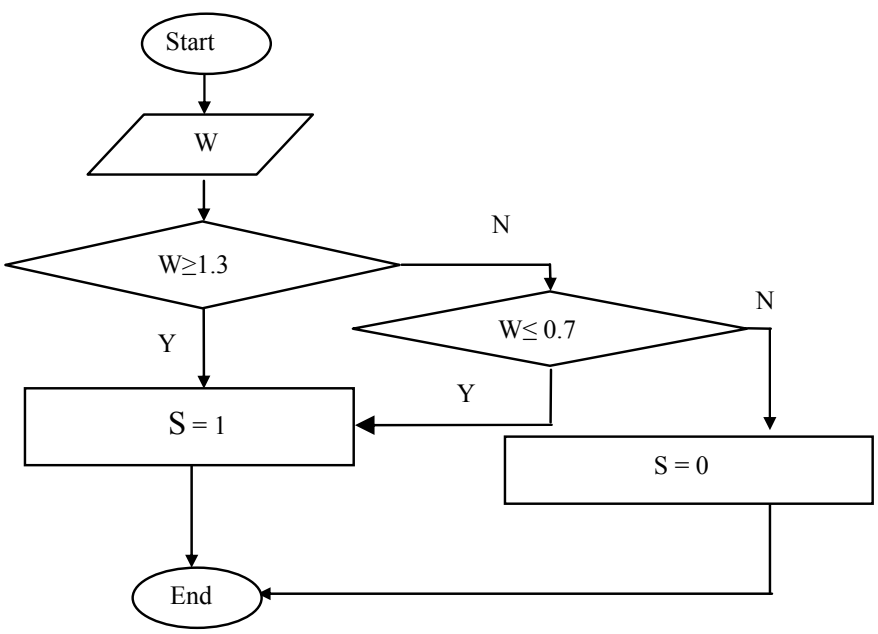

Fig. 6. Flowchart for control signal generation of FESS
For example, if the rotor speed of the FESS (W) is $\geq 1.3$ p.u. or it is $\leq 0.7$ p.u., then the storage system has excessive or shortage of energy to provide to the grid. In these extreme cases, no power will be absorbed or supplied by the FESS. The smoothing performance will be affected in these cases, but this control scheme will prevent the system from reaching instability.

\section{Simulation Results}

Figure 7 (a) shows the real wind speed data which is used for simulation in PSCAD/EMTDC. From this figure it is seen that the wind speed fluctuates between a high wind speed and low wind speed in a short period. The run time for the simulation was 750 seconds.

It was investigated earlier that an FESS system with $\mathrm{J}=100$ shows better smoothing performance and is able to ensure sufficient energy delivery at different operating conditions. It was also found that a small energy storage system with $\mathrm{J}=30$ second is not sufficient enough to smoothen the power fluctuation as well as maintaining system stability if the control strategy remains the same. The proposed control is designed in such a way that the energy of FESS varies within the range close to 0.75 p.u. Fig. 7 (b) shows that the wind generator output power which varies according to the wind speed. The predicted output powers, smoothed grid power along with the final reference power are also shown in the same figure. The power supplied to the grid exactly follows the final output power reference. The rotor speed and the stored energy in FESS are shown Fig. 7 (c) and Fig. 7 (d) respectively. If the stored energy level of FESS is not within the range (45-85) \% of the rated energy level then the reference is corrected by a multiplying factor as shown in the look up table. The multiplying factor from the look up table varies according to the level of available stored energy in the FESS and it is shown in Fig. 7 (e). Whenever the stored energy level is varying in range close to its maximum/minimum limit, the smoothing performance deteriorates which is expected due to the use of small energy storage capacity. For example, around (500-550) second, the stored energy level almost reaches to its minimum level while discharging. If the output power reference is not modified according to the proposed control scheme shown in this paper, the speed of FESS shown in Fig. 7 (c) will go beyond its operating range and the system will collapse. The advantage of the proposed control scheme lies in the fact that, the overall system smoothness is degraded a little in this kind of situations, but still it is capable to supply smooth power to the grid.

Response for the active power of FESS is shown in Fig. 7 (f). The FESS supplies or absorbs the real power according to the output power reference and hence smoothes the total power supplied to the grid. In addition, the total reactive power supplied from DFIG is shown in Fig. 8 which keeps wind generator terminal voltage constant as seen in Fig. 9. The grid side inverter can also maintain constant voltage of the DC-link as shown in Fig. 7 (i). 

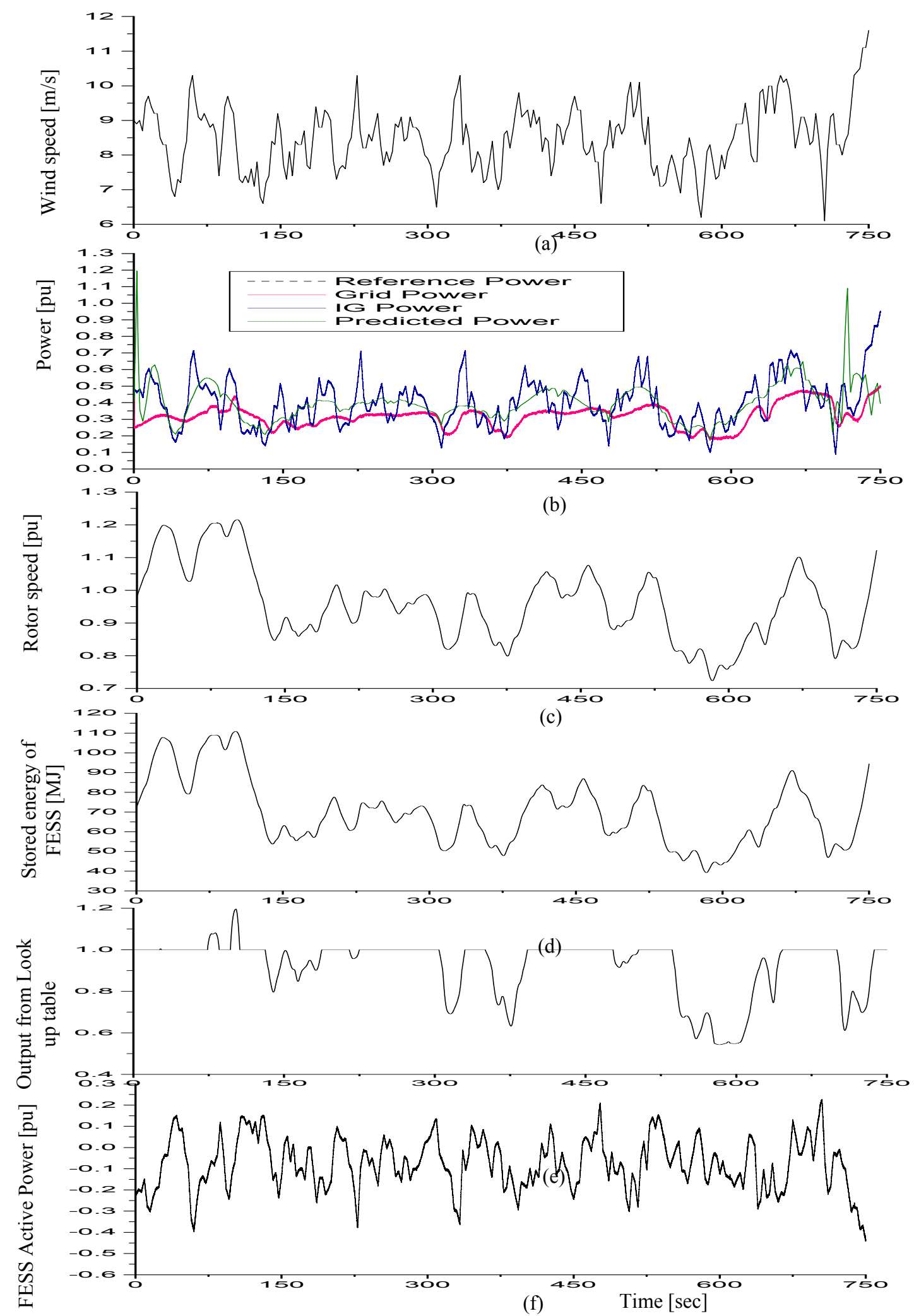

Fig. 7. System Responses (a) Wind speed (b) Error between actual and predicted wind speed (c) Final output power reference, Grid output power, WF output power (d) Stored energy of FESS (e) Look up table (f) FESS active power 

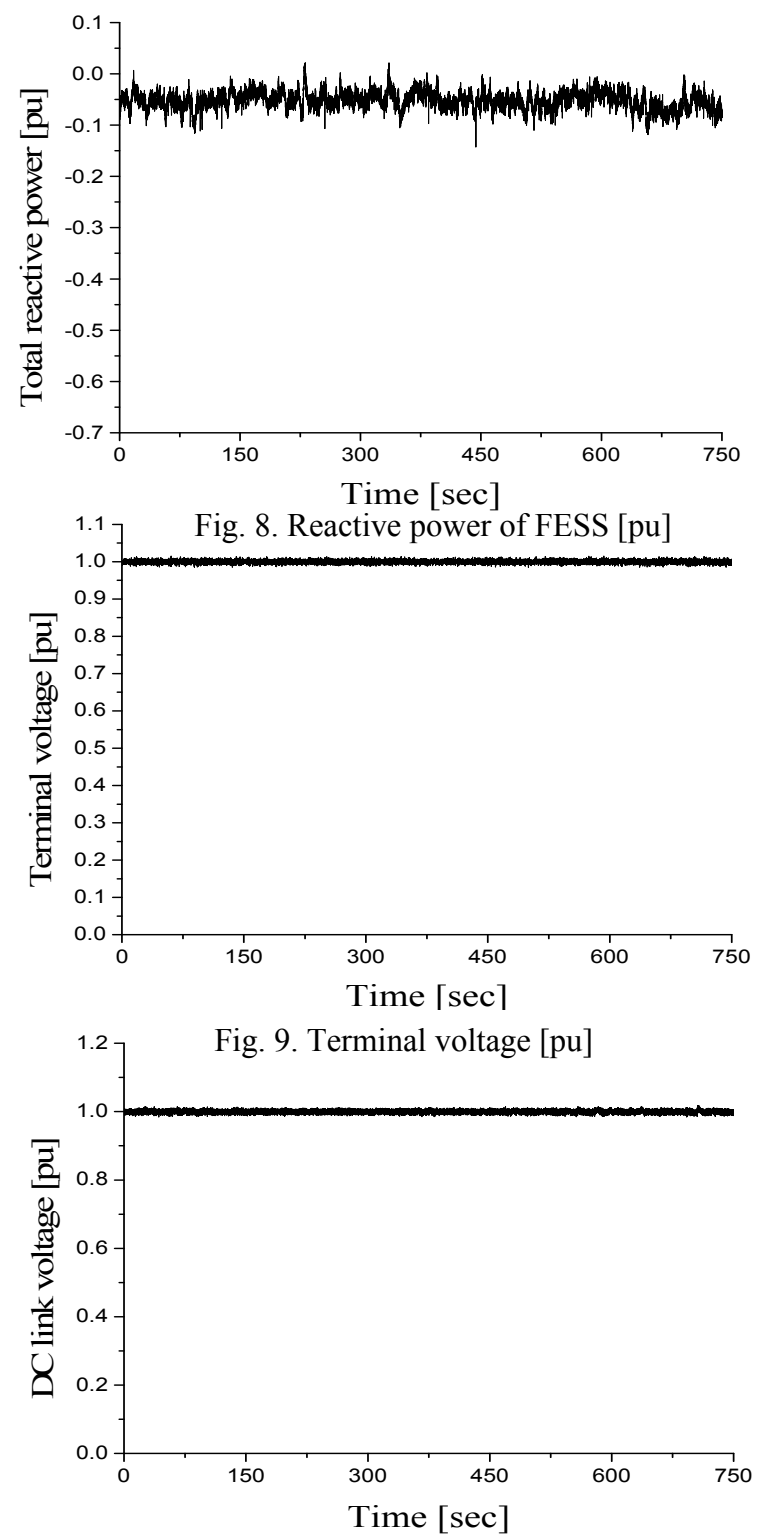

Fig. 10. DC link voltage [pu]

\section{CONCLUSIONS}

This paper has proposed a new control strategy of FESS to mitigate the fluctuation in the output power of the grid using short -term ahead wind speed prediction scheme. It has been shown that prediction of the wind speed and modification of the output power reference accordingly makes the FESS more effective and reduces the fluctuation of output power efficiently. The system cost can also be kept minimum by optimum use of small capacity flywheel energy storage system.

\section{ACKNOWLEDGEMENT}

The first author would like to acknowledge Electric Machine LAB, Kitami Institute of Technology, Japan for giving permission to use real wind speed data.

\section{REFERENCES}

[1] Global Wind Energy Council.GWEC latest news 2010, http://www.gwec.net

[2] X. Wang, G. Siderators, N. Hatziargyrion and L. H. Tsoakalas, "Wind Speed Forecasting for Power System Operational Planning," International Conference on Probabilistic Methods applied to Power System, pp 470-474, Sep 12-16, 2004.

[3] I. Moghram and S. Rahman, "Analysis and Evaluation of Five ShortTerm Load Forecasting Techniques," IEEE Trans. on Power Systems, vol. 4, no. 4, pp 1484-1489, Oct 1989.

[4] K. B.Song, Y. S.Beak, D. H. Hong and G. Jang, "Short-Term Load Forecasting for The Holidays using Fuzzy Linear Regression Method," IEEE Trans. on Power Systems, vol. 20, No. 1, pp 96-101, Feb 2005 .

[5] A. Sfetsos and C. Siriopoulos, "Time- Series Forecasting of Averaged Data with Efficent," IEEE Trans. on Systems,Man and Cybernetics, vol. 35, No. 5, Sep 2005.

[6] S.M. Muyeen, M.H. Ali, R. Takahashi, T. Murata and J. Tamura, "Wind Generator Output Power Smoothing and Terminal Voltage Regulation by Using STATCOM/ESS."

[7] R. Takahashi and J. Tamura, "Frequency Control of Isolated Power System with Wind Farm by using Flywheel Energy Storage System," International Conference on Electrical Machines, Paper ID 1410, 2008.

[8] PSCAD Manual, Manitoba Research Center, Canada, 1994.

[9] R. Takahashi, J. Tamura, M. Futami, M. Kimura and K. Idle, "A New Control Method for Wind Energy Conversion System Using Double Fed Synchronous Generators," IEEJ Trans. Power and Energy, Vol.126, No.2, pp.225-235, 2006 (in Japanese).

[10] R. D. Fernandez, P.E. Battaiotto, and R. J. Mantz, "Wind Farm NonLinear Control for Damping Electromechanical Oscillations of Power Systems," Renewable Energy, Vol. 33, pp. 2258-2265, 2008.

[11] K.E. Okedu, S.M. Muyeen, R. Takahashi, and J. Tamura, "Comparative Study between Two Protection Schemes for DFIGbased Wind Generator," Proceedings of International Conference on Electrical Machines and Systems, pp. 62-67, 10-13 Oct. 2010.

[12] K. E. Okedu, S.M. Muyeen, R. Takahashi and J. Tamura "Stabilization of Wind Farms by DFIG-based Variable Speed Wind Generators," International Conference on Electrical Machines, pp. 464-469, 2010

[13] T. Sun, Z. Chen and F. Blaabjerg, "Transient Stability of DFIG Wind Turbines at an External Short Circuit Fault," Wind Energy Journal, Vol. 8, pp. 345-360, 2005.

[14] G. Li, S. Cheng, J. Wen, Y. Pan and J. Ma, "Power System Stability Enhancement by a Double-fed Induction Machine with a Flywheel Energy Storage System," IEEE Power Engineering Society General Meeting, 2006.

[15] R. E. Walpole, R. H. Myers, S. L. Myers and K. Ye, Probablity \& Statistics for Engineers \& Scientists, Eighth edition, Upper Saddle River, NJ:Pearson Education, 2007, pp. 445-509. 